\section{Questión}

Periodismo / Comunicación ISSN 1669-6581
- Av. $44 \mathrm{~N}^{\circ} 676,1^{\circ}$ piso

CP 1900 - La Plata - Argentina

www.perio.unlp.edu.ar/question

Canciones para escuchar en Pandemia

Daniel Heffes

https://doi.org/10.24215/16696581e401

\title{
Canciones para escuchar en Pandemia
}

\section{Songs to listen to in Pandemic}

Daniel Heffes

Médico endocrinólogo. Conductor radial desde 1985, es un gran difusor de música popular. Condujo diversos programas en radios de la ciudad de La Plata (Provincia, Universidad, FM Futura) y ha colaborado en ciclos en FM La

Tribu, Radio Municipal y Nacional.

Conocedor, fundamentalmente de la música hispanoamericana, realiza desde su programa actual, La Cofradía en

Radio Universidad de La Plata, una tarea invalorable de difusión de esas melodías olvidadas por la cultura oficial. Semanalmente, rescata a los más talentosos artistas, los textos y las músicas que forman parte del acerbo cultural de cada pueblo, poniendo especial énfasis en la palabra y seleccionando canciones de intérpretes, poetas y compositores que le dan vida propia a sus obras.

\section{Listado de canciones}

https://open.spotify.com/playlist/5YHImVvl4534MQGaKHNIx8?si=hJSxSQiCQS2Z7tR-sITHrQ 